\title{
Tibiofemoral kinematics: the effect of footwear and foot orthoses during running
}

\author{
Laura Hutchison", Rolf Scharfbillig, Hayley Uden, Chris Bishop \\ From Australasian Podiatry Council Conference 2013 \\ Sydney, Australia. 2-5 June 2013
}

\section{Background}

The knee is the most common site of running related injuries (42.1\% of all injuries). Orthoses are thought to manage knee pain by reducing internal tibial rotation as the subtalar joint pronates. However, the influence of the footwear that orthoses are placed in is often ignored. This study aimed to determine the immediate effects of footwear and foot orthoses on transverse plane rotation of the tibiofemoral joint during the stance phase of running.

\section{Methods}

An experimental, within subjects, repeated measures design was used. Three-dimensional tibiofemoral kinematics were estimated in the transverse plane by surfacemounted markers as asymptomatic participants $(n=14)$ ran in four randomised conditions; neutral shoe, neutral shoe with customised orthoses, neutral shoe with prefabricated orthoses, and a stability shoe. Peak internal/external rotation joint angles and ranges of motion (ROM) during loading response, midstance and propulsion were determined. Immediate subjective comfort was also recorded.

\section{Results}

Significant main effects of condition were observed for all outcomes except tibiofemoral ROM during loading response $(P<0.05)$. All significant differences occurred between the stability shoe and another condition, with less tibiofemoral internal rotation in the stability shoe (mean difference ranged between $\left.1.7^{\circ}-6.1^{\circ}\right)(P<0.05)$. The neutral shoe with prefabricated orthoses was reported as more uncomfortable than all other conditions.

\footnotetext{
* Correspondence: hutly001@mymail.unisa.edu.au

School of Health Sciences, Division of Health Sciences, University of South Australia, Adelaide, SA, 5000, Australia
}

(C) 2013 Hutchison et al; licensee BioMed Central Ltd. This is an Open Access article distributed under the terms of the Creative Commons Attribution License (http://creativecommons.org/licenses/by/2.0), which permits unrestricted use, distribution, and reproduction in any medium, provided the original work is properly cited. and take full advantage of:

- Convenient online submission

- Thorough peer review

- No space constraints or color figure charges

- Immediate publication on acceptance

- Inclusion in PubMed, CAS, Scopus and Google Scholar

- Research which is freely available for redistribution 